\title{
Securing Social Security Disability Insurance (SSDI): Overcoming Challenges
}

\section{Michelle Cho $^{1 *}$ | Edgar Raymond Miller III ${ }^{2}$ | Jodi B Segal ${ }^{2}$ | David M Levine ${ }^{2}$ | Lee R Bone ${ }^{3}$}

\section{*Correspondence: Michelle Cho}

Address: ${ }^{1}$ Department of Public Health Studies, Johns Hopkins University, Baltimore, Maryland 21218, USA; ${ }^{2}$ Division of Internal Medicine, Johns Hopkins University School of Medicine, Baltimore, Maryland 21205, USA; ${ }^{3}$ Department of Health, Behavior and Society, Johns Hopkins Bloomberg School of Public Health, Baltimore, Maryland 21205, USA

e-mail $\bowtie$ : mcho30@jhu.edu

Received: 20 September 2020; Accepted: 14 October 2020

Copyright: (C) 2020 Cho M. This is an open-access article distributed under the terms of the Creative Commons Attribution License, which permits unrestricted use, distribution, and reproduction in any medium, provided that the original work is properly cited.

\section{ABSTRACT}

People with disabilities comprise a large and vulnerable population in the United States who are entitled to disability benefits under the Social Security Disability Insurance (SSDI) program provided by the federal government. However, there are many logistical and bureaucratic barriers to the application process, particularly the system and individual level barriers that can delay patients from having access to the income and healthcare necessary for securing their wellbeing. The strategy of establishing important personal relationships with the key decisionmakers of the application process is key to expedite and increase the likelihood for the receipt of disability benefits.

Keywords: SSDI, Social Security, Disability Benefits, Application, Relationship, Follow-Up, Monitoring

\section{Introduction: Receiving Disability Benefits in the U.S}

In a 2018 survey conducted by the Center for Disease Control, one in four U.S. adults has a disability (Okoro et al., 2018). With the high prevalence of disability in the United States, access to social insurance protection and disability benefits that are administered by the Social Security Disability Insurance (SSDI) program of the Social Security Administration is crucial because it provides a safety net and financial lifeline for those with disabilities and their families who tend to have less income and wealth to meet accruing medical expenses and lost income (Favreault et al., 2013).

SSDI provides income, work incentives/services, and health care coverage to disabled individuals based on their earnings during their years of employment prior to the development of their disability. 
The 2020 monthly average income from SSDI is \$1258 (Allsup, 2019). And, in order for a disabled person to apply for Medicare they must first be on SSDI for a 24-month qualifying period. To qualify for SSDI, claimants must meet the definition of disability, where their reported condition disables them for at least 12-months, and it is impossible for them to do any form of work. This decision is jointly made by the Social Security Administration and the State Disability Determination Services (DDS) after reviewing all medical evidence and diagnoses (Lang, 2020).

In 2018, out of the 2 million people that apply for SSDI each year, only a third of the initial applications for SSDI disability benefits were approved, and a third of the denied claimants appealed the decision (Allsup, 2019; Smalligan and Boyen, 2019). Traditionally, the application process has proven to be quite laborious and often results in a majority of patients finding out that they are not eligible.

Barriers to applying for SSDI and receiving benefits in a timely manner can occur across the individual, community, system, and policy levels. Most claimants spend two to four years navigating the application and appeals levels of SSDI and face otherwise avoidable anxiety and financial insecurity (Allsup, 2019; Smalligan and Boyen, 2019). Although the administration provides a fast-track for people with severe diagnoses or terminable illnesses, there are still financial and geographic restrictions and the cost- and time-expensive inefficiencies of the system like transportation, accessibility to application offices, correspondence by mail, technology, its duplicative stages and incentivization of representatives of claimants to prolong the application process (Smalligan and Boyen, 2019; Gettens J et al., 2018; Glending ZS et al., 2018; CRFB, 2018; Grezler, 2015).

Many of the individuals responsible for handling the SSDI application are not completing the process in a timely way because they are not fully trained, supervised, being overworked and/or underappreciated to the claimant's disadvantage (SAMHSA). This lack of supervision and appreciation towards the SSDI staff (managers and supervisors) of the initial application process contributes to the reported state average application processing period of 2 years. And, this report focuses on the importance of establishing relationships between the federal employees and the claimants based on a successful example that acknowledges the contributions of each SSDI staff of the system. The described process in this report can reduce the average timeline of the SSDI application of 2 years to 2 months by engaging all persons involved in the process with an emphasis establishing personal relationships (Foote A et al., 2018). Personal narratives promote empathy and compassion, offer insights into the lives of service users, and provide a visual and experiential example of the relationships in both educational and healthcare settings (Legere L et al., 2013; Langer and Ribarich, 2009). By highlighting the personal experience of a case-study's successful timely receipt of disability benefits, this report aims to provide claimants and their caregivers with the steps they can take to address the flawed accessibility 
and accountability system of the SSDI process in the state of Maryland. Community healthcare leaders like doctors, trainees, schools of medicine and nursing, politicians and social workers are also encouraged to learn by example on improving the efficiency of SSDI system that is financed by taxpayers.

\section{Case Study: Building Relationships}

For a successful, efficient processing of the application, claimants must fully understand what SSDI requires and have access to instructions on how best to apply. The outlined steps this case-study followed demonstrates the key strategy of establishing personal relationships between the claimant and the decision makers of the SSDI application process. Formal and informal relationships among the field offices (FOs) and Disability Determination State offices (DDSs) of Social Security with service providers have shown to increase the efficiency of the application process (Smalligan and Boyen, 2019).

1. Gather Information - Presenting a Strong Case with Complete and Comprehensive Medical Documents

Gathering accurate and extensive medical information and documents establishes a claimant's medical eligibility: the medical determinable impairment(s); the duration of the disability; and functional information of the claimant's altered state of performance (Lang, 2019-2020; SSA, 2018). These forms must be comprehensive thereby placing a significant amount of responsibility on physicians who sometimes do not fill out the forms with the proper language. Up to date medical records; consistent engagement with local health care providers; and, journaling daily ailments, illnesses, and pains are recommended (SSA, 2018).

\section{Begin the Process - Visit a Local Social Security Office In-Person}

If possible, visit a nearby Social Security office (field/state offices or resident stations) beginning with meeting with the guard to determine the best time (when it is least crowded) to visit the office. Schedule ample time for the visit. The aim of this visit is to establish a prospective filing date, the official date of initial contact with Social Security in which claimant indicates an intent to file for disability benefit and can influence the start of SSDI payments. Once the date is set, claimants have 60 days to submit the application packet to the administration (USICH, 2015; SAMHSA, 2020).

If the claimant has difficulties going to the office in-person because of the pandemic as well as geographical, familial, and health-related constraints, call the main office and determine the final application reviewer to make sure the application goes through to the next level. 


\section{At the Appointment, Completing the Application}

At the appointment the assigned disability examiner/clerk will verify and record the claimant's technical eligibility, insured status and other nonmedical eligibilities in an electronic system. Before submission, verify that they have all the information they need (Foote A, et al., 2018). This document will then be reviewed by the Disability Determination Services that ultimately determines the claimant's eligibility and qualification for a fast track (e.g. compassionate allowance, dire need, and terminal illnesses) for SSDI, especially if the applicant is severely ill (SSA, 2020).

Having an up-to-date mailing address/P.O. Box is also recommend since Social Security primarily communicates with its clients via mail (SAMHSA, 2020).

4. Assure Application Submission Has Been Entered into the System with the SSA Office by Positive Reinforcement

Social Security offices (field offices, state offices or resident stations) are the primary points of contact for in-person interaction with the public for social security benefits. The office staff consist of Operations Supervisors, managers, claims and service representatives, and trainees who take in claims, develop the evidence, and send in the application. The aim, however, is to take advantage of the vertical hierarchy of the SSDI office (Fig. 1) by walking the application 'up the ladder' (Office of the Inspector General, 2013).

Request to see the clerk's supervisor to relay praise of the clerk's assistance and patience and assure that the application has been processed and sent to the correct Disability Determination State (DDS) office (Office of the Inspector General, 2013). In conversation with the supervisor, personally praise the clerk again and ask if the paperwork has been processed (assure that the application has been sent to the Disability Office). Then ask the supervisor to speak with the supervisor of the office.

In conversation with the office manager, praise the clerk's supervisor, assure the application, and ask to be referred to a member of the DDS (Fig. 2):

- (Insert name of previous staff member) did a good job, what are the next steps to process the application?

- To which Disability Determination State (DDS) office has the application been referred to?

- $\quad$ Could I be connected to a staff member of the DDS? Ask them for their full name and extension). Or search the state Disability determination Services website and contact their office via the listed number and address. 


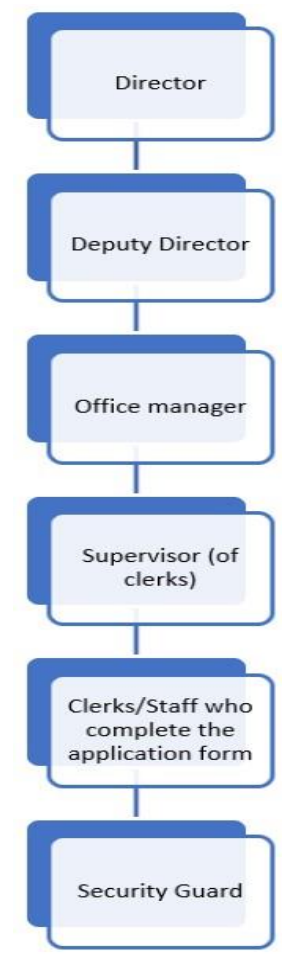

Figure 1: Structure of the Social Security Field Office

\section{Praise}

Assure application

Ask to be referred

Figure 2: In Conversation with the Federal Staff

5. Regular follow-ups and continuing relationship with the state's Disability Determination Services (DDS)

Connect with the staff member of the DDS, ask them for their full name and extension, and commit to regular follow-ups on the status of the application, during its review. This step acts to assure as another checkpoint of the completion of the application. Before entering into the business of following up, prioritize checking in with the DDS staff member first with asking them how they are with sincerity:

- How are you doing today?

- Has all the information needed to complete the application been received?

- What more information is needed?

- When will they act upon your request?

Most DDS will request additional medical evidence and information from the client often in the form of an Activities of Daily Life questionnaire many applicants fail to not be specific enough on (SSA, 2018). Inadequate evidence will delay the process and will result in the DDS's arrangement for the administration to purchase a consultative examination by phone or by mail to obtain the necessary 
evidence (Greszler R, 2015). Despite the discomfort clients may experience when disclosing their medical histories, ensuring that the decision makers at each stage have a comprehensive, up-to-date diagnosis of the claimant plays an integral role (CFRB, 2018).

Once the application is approved by the DDS, SSDI benefits are given.

Table 1: Steps Taken to Secure SSDI (Lang K, 2020; SSA, 2020; SAMHSA, 2020; Okoro CA, et al., 2018)

\section{Gather Information - Presenting a Strong Case with Complete Medical Documents}

Gather information and present a strong case with complete, comprehensive medical documents, particularly of those prepared by the claimant's physicians. Be as thorough as possible.

Refer to the Adult Disability Checklist to figure out the formal documents (e.g. birth certificate and Social Security card) needed to apply: https://www.ssa.gov/hlp/radr/10/ovw001-checklist.pdf

The strongest cases are presented as a narrative account of the claimant's personal treatment history (SAMHSA 2020).

\section{Begin the Process - Visit a Local Social Security Office In-Person}

Begin the application process by visiting a nearby Social Security office in-person. It is important to go in-person to begin establishing the personal connections necessary for a timelier processing of the application.

The application process can also be phone, mail, or online.

Online applications do not require an appointment and efficiently allow individuals to complete their applications at their own pace but does not guarantee the timely receipt of the benefit compared to applications that are done in-person.

*In circumstances prior to the COVID-19 outbreak.

\section{At the Appointment, Completing the Application}

Verify the insured status and other nonmedical eligibilities at a nearby Social Security office with a disability examiner/clerk. Answer questions with a structured interview - recorded online on a computer. Having an up-to-date mailing address/P.O. Box is also advised since it is the primary means by which Social Security communicates with its clients.

\section{Assure Application Submission Has Been Entered into the System with the Social Security Office by Positive}

\section{Reinforcement}

Seek the clerk's supervisor and ideally work your way up to the field site operation supervisor of the office by means of relaying praise of staff member's assistance to their supervisor or manager and assuring that the application has been sent to the DDS office, the process center.

To the clerk: Thank you so much for being so patient (e.g. when I was searching for my son's social security number). I would like to speak to your supervisor to tell them how helpful you've been to me...

To the supervisor (of clerk): (Clerk) was incredibly helpful. I wanted to also ask you.

Where am I in the application process?

How does the timeline look like?

To the office/district manager (or the deputy director of social security): Repeat the process with the supervisor along with the request to be connected with a staff member at the DDS.

\section{Regular follow-ups and continuing relationship with the state Disability Determination Services (DDS)}

Follow-up regularly and establish a relationship with the referred staff member the state's Disability Determination Services (DDS), again by means of positive reinforcement, to assure the completion, where it is entered into the system with all the correct information, and timeline of the application. 


\section{Discussions: Reinforcement and Follow-Up}

The steps the case-study has taken provide guidelines for building relationships and follow-up. These guidelines provide the means to regularly support and recognize the federal employees who have a significant influence over the outcomes of the application by implementing personal, face-to-face (if possible) positive reinforcement and follow-up from start to finish. In health behavior changes interventions, showing human support is an important component to the effectiveness and adherence of both face-to-face and online interactions and the same principles can applied in claimants building a supportive accountability into the federal system to obtain their SSDI benefits (Sanatarossa et al., 2018).

Face-to-face interactions are observed as a better alternative to online applications because despite online applications being increasingly efficient and convenient, these services so far can only guarantee saving the few days it may take to schedule an appointment and certain cases may not qualify (Shane, 2020).

By paying attention to setting the necessary interactions, the case-study was able to ensure that their application was not lost, sent to the correct offices, and validate that it has the complete and accurate information required for a timelier processing. The face-to-face positive reinforcement is the acknowledgment of the staffs' work and a means to hold them accountable in case there may have been incomplete submission of the application in the many steps required. Federal workers were more open to provide the application with the time and care it demanded when given positive feedback, especially when it is relayed to their supervisors or managers who can offer them greater benefits in return for their better work performance and improve their feeligns of contributing to their organization's productivity (Lietão J et al., 2019). Although, the process of intentionally establishing these face-to-face, personal relationships to attain a timelier benefit in the system is arguably self-serving, manipulative and bound to spark controversy, but it is efficient for the claimant's sake.However, the timelier receipt of the case is also attributed to the severity of the case-study's disability that tend to be fast-tracked in the application process.

The steps outline the checkpoints claimants can create to assure the processing of the application and address the inefficient, flawed accountability system of the SSDI process that still faces key management challenges in its human capital with the ongoing retirement wave and hiring freeze; incorporation of the modern concept of disability in its programs; modernization of information technology services and information security; and evaluation of its physical infrastructure placement (SSA, 2017; Shane, 2020). Target populations that are at a severe disadvantage for accessing SSDI like the poor, illiterate, and mentally disabled can benefit the most from these steps (Goldman et al., 2018; 
SSA, 2016). And, this method can also be applied to the processes of finding doctors or for any benefits.

\section{Conclusion}

The earlier receipt of SSDI benefits in this presented case-study can be attributed to the continual follow up and monitoring of each step to accelerate the traditionally slow application process via building relationships and communication expectations and the severity of the diagnosis of the claimant's disability and the face-to-face interactions (e.g. building a relationship with the office manager) that are more difficult to achieve in the present crisis. Building relationships and communication expectations are promising means to build accountability to an otherwise dysfunctional system and provide claimants with more sustainable resources by these connections to people working in institutions and organizations.

\section{Acknowledgments}

This is in honor of Lee Bone's son Robert R Bone who died from early onset dementia and was on SSDI. We would like to extend our sincere gratitude to Elizabeth Caroline Mason, the Medical Relations Director from the Maryland Disability Determination Services, and her staff for the assurance they have provided Bone in helping secure SSDI for her son. We would also like to acknowledge the help of Erica Brown as a contributor for lending us her insight based on her previous experience working in SOAR and the techniques the program used to make the processing of SSDI applications more efficient. Dr. Bone and Michelle Cho were in charge of writing the paper with Dr. Miller, Dr. Segal, and Dr. Levine as the co-authors who have provided guidance in determining the applications this manuscript may have in the medical education and practice.

\section{References}

Allsup. More than 800,000 waiting for social security disability hearings, wait times are declining but still average 18 months. Global Newswire 2019.

Committee for a Responsible Federal Budget (CFRB). Social security disability adjudicative reform: ending the reconsideration stage of SSDI adjudication after sixteen years of testing and enhancing initial stage record development. [internet]. 2018. [cited 2020 July 2]. Available from http://www.crfb.org/sites/default/files/dubin.pdf

Favreault MM, Johnson RW, Smith KE. How Important is Social Security Disability Insurance to U.S. Workers. Urban Institute 2013.

Foote A, Grosz M, Rennane S. The effect of lower transaction costs on social security disability insurance application and participation. Journal of Policy Analysis and Management 2018; 39: 99-123.

Gettens J, Lei P, Henry AD. Accounting for geographic variation in social security disability program participation. Social Security Bulletin 2018; 78(2). 
Glendening ZS, McCauley E, Shinn M, Brown S. Long-Term Housing Subsidies and SSI/SSDI Income: creating healthpromoting contexts for families experiencing housing instability with disabilities. Disability Health J. 2018; 11(2): $214-220$.

Goldman H, Frey W, Riley J. Social security and disability due to mental impairment in adults. Annual Review of Clinical Psychology 2018; 14: 453-469.

Greszler R. Time to Cut Out the SSA as middleman in SSDI representation. Heritage Foundation Issue Brief $2015 ; 4489$. Available from https://www.heritage.org/budget-and-spending/report/time-cut-out-the-ssa-middleman-ssdi-representation

Konkel F. 4 million Americans waited over an hour in line at social security field offices in 2019. <https://www.nextgov.com/cio-briefing/2020/07/4-million-americans-waited-over-hour-line-social-security-field-offices$2019 / 167270 />$

Lang K. Apply, Deny, Appeal: the difficult process of claiming disability benefits. Generations: JASA 2019-2020; 43: 18-24

Langer N and Ribarich M. Using narratives in healthcare communication. Educational Gerontology 2009; 35(1): 55-62.

Legere L, Nemec P, Sarbrick M. Personal narrative as a teaching tool. Psychiatric Rehabilitation Journal 2013; 36(4): 319321.

Leitão J, Piereira D, Gonçalves Â. Quality of work life and organizational performance: workers' feelings of contributing, or not, to the organization's productivity. 2019, 16(20).

Office of the Inspector General: Social Security Administration. Audit report: Field office performance.Office of the Inspector General: Social Security Administration 2013.

Okoro CA, Hollis ND, Cyrus AC, Griffin-Blake S. Prevalence of Disabilities and Health Care Access by Disability Status and Type Among Adults — United States, 2016. MMWR Morb Mortal Wkly Rep 2018; 67: 882-887.

SAMHSA SOAR TA Center. SOAR tools and worksheets, viewed 3 July ,2020, https://soarworks.prainc.com/article/soartools-and-worksheets

Sanatarossa S, Kane D, Senn CY, Woodruff SJ. Exploring the role of in-person components for online health behavior change interventions: can a digital person-to-person component suffice? J Med Internet Res 2018; 20(4).

Shane. How to apply for social security disability benefits online, viewed 25 June, 2020. https://www.disabilitybenefits-help.org/blog/applying-social-security-disability-online

Smalligan J and Boyen C. Improving the Social Security Disability Determination Process. UI 2019.

Social Security Administration (SSA). Disability determination process, viewed 24 June, 2020, <https://www.ssa.gov/disability/disability.html>

SSA Organizational structure of the social security administration viewed 24 June, 2020. https://www.ssa.gov/org/

SSA. Accounting for geographic variation in social security disability program participation. Social Security Bulletin $2018 ; 78(2)$.

SSA. Homeless with schizophrenia presumptive disability pilot evaluation. Social Security Bulletin 2016; 76(1).

SSA. SSA'S FY 2017 agency financial report. SSA 2017.

U.S. Interagency Council on Homelessness (USICH) Federal work group. Key strategies for connecting people experiencing homelessness to SSI/SSDI. 2015. Available from https://www.usich.gov/tools-for-action/key-strategies-forconnecting-people-experiencing-homelessness-to-ssi-ssdi/ 